\title{
Lenses on metacognition: Teachers' perceptions toward strategies in reading in a Pakistani context
}

\author{
Mansoor A. Channa ${ }^{\mathrm{a}, \mathrm{b}^{*}}$, Zaimuariffudin S. Nordin ${ }^{\mathrm{a}}$, Insaf A. Simming ${ }^{\mathrm{b}}$, \\ Ghulam S. Buriro ${ }^{\mathrm{b}}$ \\ a Cognitive Sciences Department, University Malaysia Sarawak (UNIMAS), Sarawak. Malaysia \\ ${ }^{\mathrm{b}}$ Quaid-e-Awam University of Engineering, Science, and technology, Nawabshah, Pakistan \\ *Corresponding author. E-mail: mansoor.english@yahoo.com
}

\begin{abstract}
The research in the field of metacognition for developing reading is not new; metacognition has been used for many years to identify ways to develop students' reading comprehension. Most previous research has addressed either primary or secondary level students. However, notably few studies have been conducted at the undergraduate level. This study has attempted to initiate strategies to assist first-year engineering students in developing their reading abilities within a Pakistani context. The primary objective of this research was to identify what strategies first-year engineering students use in developing their reading at Quaid-e-Awam University of engineering science and technology in Pakistan. This study used qualitative instruments that included semi-structured interviews with teachers and classroom observations during read-aloud sessions. The data were organized through NVivo version 8 for obtaining nodes, codes, and main themes for interpreting the results. The results of this study demonstrated that teachers should use metacognitive strategies for developing students' reading abilities. Findings also revealed that reading strategies, such as text scanning, guesses from contextual clues, drawing on prior knowledge, and using a dictionary, are the most important strategies to use for developing the reading skills and comprehension of engineering students. This study has suggested metacognitive strategies be used for promoting students' reading abilities and that teachers should design and develop more courses using these strategies to enhance the reading and listening skills of engineering students.
\end{abstract}

Keywords: metacognitive, reading strategies, comprehension development, cognitive

\section{Introduction}

This research aimed to investigate the present metacognitive strategies used by teachers from engineering departments in Pakistan to promote reading comprehension. Research on metacognition originated from attempts to develop familiarity with how students learned and believed in metacognitive strategies for the 
development of reading comprehension in the English language. According to Sternberg (1986) and Borkowski, Carr, and Pressley (1990), the word metacognition is used in educational psychology to describe a process of enabling successful student learning through the use of intelligence. Metacognition is related to thinking at higher levels by involving one's control over the cognitive processes of students engaged in learning how to read and comprehend the text. The strategies involved in metacognition are: (1) planning how to approach a reading text in terms of proper meaning, (2) monitoring reading comprehension, and (3) evaluating the students' progress in reading the text. Metacognition can be associated with Favell's $(1979,1987)$ theory, which is based on metacognitive knowledge and metacognitive experiences; metacognitive knowledge means acquired knowledge involving cognitive processes based on knowledge of person, task, and strategy. Flavell's $(1971,1976,1979,1981)$ theory of metacognition provoked debate in the field of psychology that encouraged people to initiate research in the area globally. Therefore, the research that began in the field of cognitive development with Son and Schwartz's (2002) work paved a way for carrying out research in educational psychology and cognitive sciences. This development increased study and research in the area of metacognition, "not only in academic but also in professional areas" (Zimmerman, 1998, p. 76-78).

Moreover, metacognition can be understood as the highest level of a person's mental practices used to govern thinking processes or thinking levels in order to control knowledge or experiences. Flavell $(1987$, p. 2) divided metacognition into metacognitive knowledge and metacognitive experiences, which involve a person's mental processes. Flavell's (1987) metacognitive knowledge is regarded as the "cognitive" or "psychological" knowledge that addresses the idea of controlling mental processes in certain activities. Flavell's (1987) theory was expanded upon by many researchers, who divided metacognition into three aspects: planning, monitoring and evaluating. As far as planning is concerned, Ariel, Dunlosky, and Bailey (2009) emphasized aiding students' learning process by planning to include different choices for learning activities. Palinscar and Brown (1984) similarly proposed planning before-reading procedures that include surveying and anticipating as the most important systems. Thiede, Anderson, and Therriault (2003) asserted that monitoring is the ability to comprehend students in order to make them independent learners. Independent or self-regulated readers take responsibility for their own reading and monitor their own comprehension levels. Most readers reread material in order to answer close-reading questions. Evaluating is considered by Schiff and Calif (2004) as a post-reading strategy that reveals the needs of students to summarize the core ideas for comprehension of certain material and to find supplementary evidence for outside needs.

\section{Background of the study}

The idea of metacognition in reading is complex. Dunlosky and Metcalfe (2009) stated that the area of metacognition has stimulated the interest of researchers for more than three decades. In fact, wide and profound as it seems to be, the field of brain research as it relates to learning offers colossal open doors for learners to develop metacognitive strategies. This area of research would also open new ho- 
rizons for the innovation of expansive capabilities in psycho-linguistics, cognitive training and brain research in general, and particularly in reading comprehension. This study attempted to examine the reading cognizance abilities of engineering students at one Pakistani public university. In Pakistan, English is used as the second language and medium of instruction in all educational institutions; this language is also considered as the official language of the country (Channa, 2012). Similarly, multinational companies in Pakistan prefer to recruit employees who have sound reading knowledge of English texts, as they need to be capable of reading and comprehending agreements, contracts, bonds, deals, as well as exchanging official messages and emails with seniors, managers, and co-workers, as well as in their daily businesses. Wei (2005) considered reading as the most essential tool for developing educational and professional achievement. Wei (2005) further stated that students want to comprehend textbooks and research articles in order to obtain knowledge to support their academic studies. Aebersold and Field (1997) asserted that reading is important in learning, but that most students are unable to effectively read texts due to various problems. These problems include inappropriateness of the reading, misapprehension of grammar, vocabulary problems, and poor background knowledge (Nuttall, 2000). Teachers use inappropriate reading material that does not meet the need for engineering students to expedite their reading aptitudes. Readers cannot understand long sentences in the texts due to their variety of clauses and complex forms in terms of grammatical structure. These readers also do not understand the text due to their poor background knowledge of reading. Channa et al. (2013) investigated the needs, wants, and problems of using English experienced by first-year engineering students at QUEST in Pakistan. This study investigated the reading ability of QUEST engineering undergraduates, which was found to be low. The main problems in reading were sentence structure, vocabulary in context, paragraph organization, grammatical rules (structures), prior reading and comprehension knowledge, and weak paragraph organization. The results showed that engineering students had difficulties in reading and comprehending texts.

\section{Reading and metacognition}

Reading comprehension is the basic skill necessary for students to learn the English language in Pakistan. Many attempts have been made to overcome the barriers to reading comprehension, particularly to change traditional methods of teaching reading, but few have succeeded to date. Moreover, research in developing students' reading proficiency is needed, particularly research involving metacognitive strategies, in order to make Pakistani students independent readers who can successfully achieve reading goals. One example of this necessity is demonstrated by Channa, Yossatorn, and Yossiri (2012), who conducted a qualitative study to investigate the perceptions of international students studying in medical and engineering departments in one university in Thailand. Their study used strategies as students learned the language. The findings suggested that the use of strategies does encourage students to boost their performance in language learning. Similarly, other studies (Channa \& Nordin, 2014; Channa et al., 2015; Channa \& Nordin, 2015; Channa et al., 2016) revealed that metacogni- 
tion and cognition can develop cognitive awareness and cognitive regulation of students' comprehension and ability to discover the exact meaning of academic and professional texts. Similarly, Chamot and Kupper (1989) asserted that strategies such as summarizing, evaluating, monitoring, elaborating, and deducting can be used to solve students' reading comprehension problems. However, it was unclear what (metacognitive) strategies Pakistani students used in terms of reading comprehension of English-language texts before this research was carried out. Metacognition can be associated with Favell's $(1979,1987)$ theory, which is based on metacognitive knowledge and metacognitive experiences; metacognitive knowledge means acquired knowledge involving cognitive processes based on knowledge of person, task, and strategy, and metacognitive experiences are used to control cognitive processes. Flavell's $(1971,1976,1979,1981)$ theory of metacognition provoked debate in the field of psychology that encouraged people to initiate research in the area globally. Therefore, the research that began in the field of cognitive development with Son and Schwartz's (2002) work paved a way for carrying out research in educational psychology and cognitive sciences. This development increased study and research in the area of metacognition, "not only in academic but also in professional areas" (Zimmerman, 1998, p. 76-78). Moreover, metacognition can be understood as the highest level of a person's mental practices used to govern thinking processes or thinking levels in order to control knowledge or experiences. Flavell (1987, p. 2) divided metacognition into metacognitive knowledge and metacognitive experiences, which involve a person's mental processes. Flavell's (1987) metacognitive knowledge is regarded as the "cognitive" or "psychological" knowledge that addresses the idea of controlling mental processes in certain activities. This knowledge involves a perception of cognitive positions of certain activities for controlling and accomplishing certain purposes. Flavell (1979) coined the term metacognition and defined it as a knowledge that addresses certain mental approaches and certain thoughts based on reasons that occur in the learning processes. Similarly, Piaget's (1971) cognitive development theory and Vygotsky's (1978) theory opened doors for others to work in the field. As a result, Flavell (1976) proposed that the field of metacognition involve cognition to monitor and regulate the strategy of comprehension of readers of all fields at all levels.

\section{Objectives}

The main objective of this research was to identify the difficulties or barriers that engineering students and teachers face when reading texts, as well as to identify what strategies first-year engineering students used in their reading and what strategies engineering students need to develop reading comprehension in Pakistan.

\section{Method}

In this research, qualitative research instruments were used to record the perceptions of teacher respondents regarding metacognition in reading comprehension. The main instrument was the semi-structured interview of 10 teachers. The readaloud technique was also applied through class observations in the four engineering 
departments in one Pakistani university (QUEST) to identify and investigate metacognitive strategies in reading comprehension. The researchers spent a maximum of 20 minutes and a minimum of 12 minutes with each individual for the interview. The semi-structured interviews with teachers were conducted in the months of April and May 2015 in Pakistan. These interviews were recorded using audio tape and transcribed for analysis and results. Initially, the researchers analyzed research data following Strauss and Corbin (1990) for interviews and class observation. However, NVivo software version 8 was used for undertaking and strengthening the analysis process. This NVivo software, version 8 generated the main themes for interpreting the results, which are discussed below after the demographic information of the participants.

\section{Demographic information}

In this research, the researchers undertook semi-structured interviews with ten teachers teaching in the four engineering departments in one university in Pakistan. There were seven male teachers and three female teachers teaching comprehension and including reading strategies in read-aloud sessions of the classes. These four departments included the computer system engineering department, the energy and environment engineering department, the electrical engineering department, and the mechanical engineering department. Additional demographic information about respondents is given in the table below.

Table 1. Demographic information

\begin{tabular}{lcc}
\hline & & Teachers \\
& & $\mathbf{N = 1 0}$ \\
\hline \multirow{2}{*}{ Age } & $25-30$ & 4 \\
& $31-35$ & 2 \\
& $36-40$ & 2 \\
& $41-45$ & 2 \\
\hline Gender & Male & 7 \\
& Female & 3 \\
Education & B.E degree & 3 \\
& Master & 4 \\
& PhD & 3 \\
Length of service & $1-5$ & 3 \\
& $6-10$ & 2 \\
& $11-15$ & 3 \\
& $15-20$ & 2 \\
\hline Department & mechanical engineering & 2 \\
& electrical engineering & 3 \\
& energy and environment engineering & 3 \\
& computer system engineering & 2 \\
\hline
\end{tabular}




\section{Results}

This study revealed the metacognitive strategies with potential benefit to develop comprehension in academic reading, as well as reading of general texts and to further students' level of reading growth. Similarly, the interview data of the informants was analyzed through NVivo software version 8 , and the following main themes presented for interpreting the study's results.

Table 2. Main themes

\begin{tabular}{cl}
\hline Level One Code & \multicolumn{1}{c}{ Level Two Codes } \\
\hline Metacognitive Strategies & 1. thinking through images of the texts \\
& 2. using prior knowledge \\
& $\begin{array}{l}\text { 3. } \text { using guesses from contextual clues } \\
\text { 4. using dictionary }\end{array}$ \\
\hline
\end{tabular}

\section{Results of teachers' interviews: metacognitive strategies}

The metacognition theory was adopted in line with Flavell's (1979) existing theory based on planning, monitoring, and evaluating as the initial themes of this study. The data gathered generated the following main themes or codes in level two as the final themes for interpreting the results.

\section{Thinking through images of the texts}

The first item of the level-two theme for metacognitive strategies is thinking through images. More than half of the informants stated that thinking involves making an overall mental picture of the text by creating mental images about headings, subheadings, and content tables of any article or book before reading. The students can form or develop thoughts or imagery about the material through the power of their imagination and form their ideas about the texts to answer certain reading tasks. Thinking can improve the methods that readers use in selecting books, articles, and material related to them. Some of the informants reported that thinking is types of mental image process involving capturing a mental picture of the text that can help students guess what was going on in terms of reading tasks. It can also assist them in discovering what they think of the texts. Three informants reported that thinking involves connecting images and texts to form the reader's concept or idea, which will assist in apprehending the meaning of the text. These interviewees reported:

"...making mental images prior to reading would be important to make initial thoughts about the article in mind...[it]would be useful to connect text with thoughts....[it]would help in understanding and increase reading speed. This [thinking] enables readers to imagine what the text would be about before the actual reading practice." [Informant Two]

"...before the beginning of reading comprehension.....students should brainstorm or imagine about the text by looking at the titles of the articles and contents of article. Actually... to me, thinking and brainstorming are the same to develop personal attachment with the text." [Informant Three] 
"I think mental images or brainstorming...both...are thinking processes. This [thinking] may be involved when readers look at the titles, subtitles and even the text in the article. Imagery would make students understand the text with personal ideas... and would help them guess what the text is about and what its purposes are....thinking helps readers to build a concept about the article and interconnect personal attachment..." [Informant Seven]

Interestingly, two of the interviewees reported that thinking involves a selfapproach process used by the readers to develop personal ideas before reading the whole article, in which they construct temporary thoughts to help them better understand the written text and increase their interest in reading for comprehension and practice in the class. Two of them noted:

“....before actual reading...readers should make their thoughts....temporary...not permanent about the text. This [thinking] strategy would develop interest in reading comprehension and they [the students] would involve themselves in reading tasks with full zest and would practice in and outside of class..." [Informant One]

"....to me...good readers do connect the authors' writing with their own thoughts about the text through thinking strategy. I direct my students to go into the world of imagination for at least few minutes before starting their readings and develop personal opinions and confirm them after reading. This strategy would increase their interest for further practice...." [Informant Nine]

However, one interviewee stated that thinking at the pre-reading stage can mislead readers into judging an article or formulating an incorrect picture of the text, which can create confusion and misapprehension and result in negative thoughts before reading. Such thoughts would slow their reading speed and possibly cause misunderstanding of the actual meaning of the texts:

"....to me...thinking about article at the beginning may cause misinterpretation and may lead [students] to draw negative pictures of the text.....this may cause uninterested behavior of a reader toward reading. I think... thinking before reading would slow reading speed and build negative thoughts...." [Informant Eight]

\section{Using prior knowledge}

Using prior knowledge is the fifth item of the level-two theme for metacognitive strategies. More than half of the interviewees reported that the use of prior information is very important for reading an article in order to understand the text and obtain information, both generally in the context of engineering books and particularly in learning to read English-language texts. Most interviewees claimed that whenever students use their prior knowledge while reading an article, they are able to predict the real meaning of the text. Additionally, using prior knowledge or personal experiences can reduce readers' stress, enabling them to comprehend the exact meaning of the passage or an article. Moreover, three of the informants assumed that personal experience or prior knowledge can be useful to help students appreciate the contexts of the written material that would increase their attention to 
the important points or themes within the text. Conversely, one of the informants reported that students who have problems or obstacles in reading cannot use their background knowledge or prior information because they cannot recollect their thoughts, memory, and personal knowledge and cannot relate these to the texts they are reading. These informants noted:

"....when students have prior knowledge of what they are supposed to read...it provides them confidence and affirmation and helps to apprehend the background of the text without problems....particularly in technical articles including engineering or science articles...." [Informant Two]

"I guide my students to practice reading with their personal experiences of the past.... this would help them to understand the context of the text when they recollect their previous knowledge and interconnect it when they are going to read an article...."[Informant Eight]

“....students experience many problems while reading, as they do not use their past experiences....using prior knowledge while reading an article would be helpful for readers to develop their understanding. If they have no idea of personal experiences to attach to the thoughts of the written text....they should try to guess the meaning while doing the reading activity..." [Informant One]

"....students should use their personal knowledge when they are going to read....prior knowledge would support them in comprehending the meaning of the text. If they do not use prior knowledge with their reading.....it would take lot of time to comprehend the meaning of the text while reading...." [Informant Four]

Interestingly, three of the informants stated that students should use their background knowledge at the time of reading an article. This would enable them to predict the real meaning of the text because prior knowledge would lessen readers' stress, allowing them to better comprehend the exact meaning of the article. These interviewees commented:

"My students always use their background knowledge when they read texts.... they know that using prior knowledge would enable them to understand the meaning of the text and would play an active role in their performance on the activity. If anyone does not know how to use their previous information, it is because of their poor reading proficiency... and they cannot comprehend the text and cannot actively take part in reading activities..." [Informant Three]

"....readers should use previous information at the time of reading an article.... this would make them capable of predicting the exact meaning through their guesses and would make them feel stress-free while reading...." [Informant Seven]

"....students should use personal experiences and personal information from the past while reading to understand the meaning of the text... if they have no knowledge or they have no previous experience on the subject... they would not interconnect their opinions 
while reading and would feel difficulty and fear of their failure....this would increase tension whenever they find texts for reading tasks...." [Informant Nine]

Interestingly, one of them stated that students can overcome their reading problems by using prior knowledge at the time of reading activities. Hence, the readers should have complete control over their thoughts and memories of their past knowledge. One of the informants commented:

".... [students] using prior knowledge can easily overcome reading obstacles of the text... students would be enabled to think, recollect their memories of their past knowledge and use them while reading a passage or paragraph...." [Informant Ten]

\section{Using guesses from contextual clues}

Using guesses from contextual clues is the sixth item of the level-two theme for metacognitive strategies. More than half of the informants agreed with this strategy and proposed that readers should guess on all difficult words and phrases in the paragraphs. This strategy would help them to understand the meaning of the text. Three of them stated that the guessing strategy would enable readers to use their opinions and thoughts to perceive the meaning of the text's ideas. If these students failed to guesstimate the sense and meaning of unknown terms or words, they would suffer and experience problems and be unable complete reading tasks on time. Two of the interviewees reported that readers should search for the important words or terms from the text and should select them for future practice and memorization. The readers can evaluate their guesses after completing their reading tasks by using a dictionary. However, one of the informants reported that students should skip all those words or terms that seem unnecessary and should focus on the essential parts of the sentence, which include subject, predicate based on action, object of a sentence, and complement in a sentence. These informants noted:

"....using the guessing strategy for difficult words and phrases would develop our reading comprehension ability...this strategy would enable us to find the accurate meaning of the text or arguments used in the passage. This strategy would help us to note and predict an appropriate connotation for all those unfamiliar words that seem very difficult, and we can evaluate our guesses after reading task completion by means of a good dictionary...." [Informant Three]

"....if my students do not know the meaning of difficult words.... I do suggest they avoid all unknown or difficult words and to practice their guessing strategy following all indications based on the contexts around the unfamiliar opinions or terms....." [Informant Six]

"My students practice reading comprehension by guessing the difficult words, phrases, terms, and sentences with difficult structure around the contextual clues of the text.... if my students do not guess the meaning and continue reading again and again, [this] would waste their time and energy and would increase their tension with the text. This occurs to those who are very weak in reading....these students need lot of attention and reading practice...." [Informant Two] 
".... when students may find difficult words; they should read hints around the passage in the text. If they fail to find clues around the context of the text....they should use dictionaries or seek peer support for obtaining knowledge of the difficult words or sentences." [Informant Four]

Importantly, two of the informants assumed that readers should search for the important words or terms from the text and should select them for future practice and memorization. The readers can evaluate their guesses after completing their reading tasks using a dictionary. Two of them claimed the following:

"...readers should read the text and select all difficult words and should refer to a good dictionary to find the meanings.... they should practice for future practice. They should memorize the meaning of all those words that they find on daily basis and apply their guessing strategy to understand the text...." [Informant Nine]

"....readers should not be disturbed to see the difficult words in text....they should select [the word], find the meaning from a mobile dictionary and practice on reading task. After completion of the reading task, they should remember words for future practice....they also should evaluate their guesses by checking meanings in the dictionary and find their guesses and see how nearly or exactly they used guesses of difficult words." [Informant Seven]

Interestingly, one of them suggested that readers should skip all those words or terms that seem unnecessary and should focus on the important parts of the sentences. These informants noted:

“....readers should be given advice to skip all unnecessary words or phrases.... they should only focus on the most important parts of the sentences, including subject, predicate, object, and complements in a sentence and should use their guesses for difficult words or terms in a reading activity around the context and interconnect their personal thoughts related to the texts." [Informant Five]

\section{Using dictionary}

The seventh item of the level-two NVivo theme for metacognitive strategies is using a dictionary. All of the informants agreed with this strategy and proposed that readers should use a dictionary to determine the meaning of difficult words in a passage. Informants also stated that in today's age of technology, students should use an electronic dictionary or mobile dictionary when they are performing reading activities in class. Most of the interviewees stated that using a dictionary would help readers evaluate the meaning of their guesses in the time allotted for an activity. Three of the informants reported that using a dictionary is the better source for developing vocabulary for their future reading needs, and as a result would also bridge the gap between low-proficiency readers and high-proficiency readers. Interestingly, one interviewee stated that using a dictionary would make a paragraph or article easy for all readers, who would get equal chances to read and find words or confirm their guesses within seconds, which could play a positive role in reading activities. The informants indicated: 
“....using a dictionary is important for academic life...so students should refer to a good dictionary when they find difficult words or phrases in the text. Using a dictionary would enhance their [students] vocabulary.... if these students would not use a dictionary while reading, they cannot confirm their guesses and would not enrich their vocabulary...." [nformant Two]

"...yeah...of course...use of a dictionary is a good method to find difficult or unfamiliar words, terms or unknown phrases which are commonly used in the text. I guide my students to consult a good dictionary, either electronic or mobile, in class to resolve their vocabulary problems in reading activities.' [Informant Five]

"....to me....reading text needs the help and support of using a dictionary in the class and outside the class practice.... this would increase the knowledge of the students to overcome reading barriers....to me...students suffer due to lack of vocabulary....students would feel peace of mind when they know or consult a dictionary in time and resolve the vocabulary problem..." [Informant Three]

".... when students do not understand the clues from certain contextual areas, we advised them to use a good dictionary to resolve the problems based on unknown words or confused structure of a sentence.... when they find the meaning of those certain problematic words, they comprehend the passage and play an active role in the reading activity in class. Therefore, using a dictionary is very important for developing reading comprehension." [Informant One]

Notably, three of the interviewees reported that using a dictionary means that students evaluate their guesses and enrich their vocabulary for future practice. Using a dictionary also bridges the gap between low-proficiency and proficient readers. For example, these informants commented:

"I often suggest my students to bring a dictionary when they have reading class and consult it when they find difficult vocabulary in the text or when they cannot perceive the meaning with the help of contextual clues.... these students know the importance of a dictionary when they have difficulty....they consult the dictionary to find different meanings...." [Informant Ten]

"....students should use a good dictionary....this would expand their vocabulary and resolve their problems in terms of words to be used as the noun, adjective, adverb in the sentence. They get the sense of multifunctional words through a good dictionary [so they can] play an active part in reading activities." [Informant Seven]

“...my students use a dictionary while performing reading tasks.... they evaluate their performance and check their guesses.... they think that the dictionary has enriched their vocabulary...using a dictionary would be important in bridging the gap between them and their proficient classmates..." [Informant Six]

Conversely, one of the informants opposed the proposal and asserted that using a dictionary would waste time. This informant stated that readers would not 
complete reading tasks within the stipulated time. They should avoid consulting a dictionary during the reading activity in class but may use a dictionary at home and memorize words for future practice. One of them asserted:

"....readers should avoid using a dictionary in class during the reading task....if they use [a dictionary] it would waste time and they would not complete the reading task in time... they should consult dictionary during leisure time and may memorize words for future practice..." [Informant Eight]

\section{Discussion}

This study is closely related to that of the research of Chumpavan (2000), which indicated that students faced great difficulties in reading and comprehension while reading. The students also had problems with a lack of prior knowledge and therefore could not correctly understand the text. Similarly, Chumpavan's (2000) study reported that students did not properly understand the texts; they had to use a dictionary and took considerable time to apprehend the texts. However, the results of the present research reported that most of the students lack background information and face great problems or barriers while reading texts. They failed to recall their background experiences or prior knowledge when they did read passages. Similarly, these students could not complete their reading tasks in time. In short, most of the students failed to make correct guesses regarding the texts and could not identify the exact meaning of the texts. The engineering informants used metacognitive strategies at QUEST in Pakistan and the way these informants adopted them to use in reading texts was studied. The present research indicated that the engineering students were completely attentive and knew about their reading comprehension strengths and weaknesses in regulating their thinking abilities while reading passages from assigned texts. The results acquired from the interviews and data from class observations of read-aloud activities suggested that the engineering respondents used metacognitive strategies to improve their comprehension and more easily apprehend the meaning of reading passages. The results of this present research are reliable and consistent compared with the results of earlier studies, which asserted that the readers always used metacognitive strategies to help enhance their reading comprehension (Chumpavan, 2000). The present study's results also helps students understand their reading proficiency and practice for its improvement. This research has shown significance in terms of strategies (metacognition) for engineering students to use in their reading practice and the processes of comprehension. These findings are regarded as consistent with the study of Chumpavan (2000), which revealed the metacognitive strategies used by Thai students studying at Illinois State University in the USA for more than two years; they were highly expert in reading comprehension. The study focused on metacognitive strategies and the findings revealed that the participants applied strategies for planning, monitoring, and evaluating their reading texts, their abilities, and their comprehension proficiency. 


\section{Conclusion}

The results of this study revealed that the informants used metacognitive strategies when they began reading comprehension activities. These strategies enabled students to read and understand the text independently. In addition, it was determined through classroom observations and verified in the interviews with teachers that the students with low reading proficiency lacked knowledge in terms of technical and general vocabulary and always felt confused at difficult parts of the text. In short, students' experience of reading problems is due to lack of vocabulary and grammatical structure problems, which decreased their interest in reading comprehension. Further, the findings of this study indicated that the engineering students should use different metacognitive strategies for planning, monitoring, and evaluating their reading and comprehension in the pre, during and post stages of reading. The results indicated that scanning, skimming, and questioning can be used when planning the reading to encourage students to take a bird's eye view of the passages. Additionally, thinking through creating mental images, selecting supporting ideas, selecting topic sentences, selecting important words, using prior knowledge, applying guesses from contextual clues, using dictionaries, following grammar rules, and rereading can be used during reading comprehension. The reading activities should be ended with summarizing, paraphrasing, and questioning as post-reading strategies to develop and promote engineering students' ability and reading speed.

To conclude, this present research supports the claims made in the past research in terms of the strategies identified and used by the informants. This present study also confirms that using metacognitive strategies improves the engineering students' comprehension levels of the texts. The informants of this study reported that they used different metacognitive strategies in order to develop understanding, which included scanning to take a bird's eye view of the text; mental images to make an overall picture of the text; and selecting main ideas, topic sentences, and important words or phrases to clarify their understanding and build new knowledge. In addition to these results, this study suggested the following recommendations:

1. It is recommended that for further studies, comparative qualitative study should be conducted involving two different universities in order to collect data regarding perceptions towards metacognitive strategies in developing reading comprehension in other fields, such as bioscience, medical science, and technical education, in order to explore at a broader level.

2. This study examined the reading problems of engineering students using metacognitive strategies. To obtain more motivating data, further research should investigate other aspects, including age and reading proficiency, gender difference and reading proficiency, task-based activities, and students' involvement in reading based on their selection of topics and subjects.

3. This study used a qualitative instrument to collect data as the major tool. However, future research should include quantitative instruments as the major instrument and qualitative as the supplemental instrument to provide more in-depth information. 
4. Students majoring in fields such as law, nursing, computer science, and cognitive sciences should be asked to participate in further studies of metacognitive strategies in reading comprehension to find the difference in the results.

5. Students majoring in areas such as ELT, Applied Linguistics, EFL, and Psycholinguistics should be asked to conduct research on metacognitive strategies for developing reading comprehension at undergraduate and graduate-level studies.

\section{References}

Ariel, R., Dunlosky, J., \& Bailey, H. (2009). Agenda-based regulation of study time allocation: When agendas override item-based monitoring, Journal of Experimental Psychology: General, 138(3), 432-447, doi: 10.1037/a0015928

Aebersold, J. A. \& Field, M. L. (1997). From reader to reading teacher. Cambridge: Cambridge University Press.

Borkowski, J. G., Carr, M., Rellinger, E., \& Pressley, M. (1990). Self-regulated cognition: Interdependence of metacognition, attributions, and self-esteem. In B. F. Jones \& L. Idol (Eds.), Dimensions of thinking and cognitive instruction (pp. 53-92). Hillsdale, NJ: Lawrence Erlbaum Associates, Inc.

Chamot, A. U., \& Kupper, L. (1989). Learning strategies in foreign language instruction. Foreign Language Annals, 22(1), 13-23. doi: 10.1111/j.1944-9720.1989.tb03138.x

Channa, M.A., Nordin, Z.S., Insaf Ali Siming, \& Ali Asgher Chandio (2016). A qualitative study of reading comprehension: An insight from Pakistani context bridging the needs of engineering students. International Journal of English Linguistics, 6(2), 85-91. doi:10.5539/ijel. v6n2p85

Channa, M.A., Nordin, Z.S., Insaf Ali Siming, Ali Asgher Chandio, \& Mansoor Ali Koondher, (2015). Developing reading comprehension through metacognitive strategies: A review of previous studies. English Language Teaching, 8(8), 181-186. doi:10.5539/elt.v8n8p181

Channa, M. A., \& Nordin, Z. S. (2015). Social cognitive theory and the zone of proximal development in the learning of reading comprehension. Science International (Lahore), 27(1), 581-585.

Channa, M. A., \& Nordin, Z. S. (2014). Identifying metacognitive strategies through learners' reading comprehension: a review of related studies. Science International (Lahore), 26(5), $2457-2460$.

Channa, M. A. (2012). Teachers' perceptions towards English language as a medium of instructions in Pakistan. Interdisciplinary Journal of Contemporary Research in Business, 4(5), 759-764.

Channa, M.A., Yossatorn, Y., \& Yossiri, V. (2012). Students' attitudes towards teachers' using activities in EFL class. International Journal of Academic Research in Business and Social Sciences, 2(5), 158.

Channa, M.A., Soranastaporn, S., Engchuan, K. S., \& Tirataradol, Y. (2013). A study of needs, problems and wants of using English of Engineering students at Quaid-e-Awam University of Engineering, Science and Technology, Pakistan. Journal of Education and Practice, 4(3), $18-26$.

Chamot, A. U., \& Kupper, L. (1989). Learning strategies in foreign language instruction. Foreign Language Annals, 22(1), 13-23. doi: 10.1111/j.1944-9720.1989.tb03138.x 
Chumpavan, S. (2000).A qualitative investigation of metacognitive strategies used by Thai students in second language academic reading. SLLT, 9, 62-77.

Dunlosky, J., \& Metcalfe, J. (2009). Metacognition. Los Angeles: SAGE.

ESL Lounge (2012). Just married. Retrieved from http://www.esl-lounge.com/student/ reading/2r5-just-married.php

Flavell, J. H. (1971). First discussant's comments: What is memory development the development of? Human Development, 14, 272-278. doi: 10.1159/000271221

Flavel J. H., (1976). Metacognitive aspects of problem solving, In L .B. Resnick (Ed.), The nature of intelligence (pp. 231-236). Hillsdale, NJ: Erlbaum.

Flavell, J. H. (1979). Metacognition and cognitive monitoring. American Psychologist, 34, 906911. doi: 10.1037/0003-066X.34.10.906

Flavell, J. H. (1981). Cognitive monitoring. In W. P. Dickson (Ed.), Children's oral communication skills (pp. 35-60). New York: Academic Press.

Flavell, J. H. (1987). Speculations about the nature and development of metacognition. In F. E. Weinert \& R. H. Kluwe (Eds.), Metacognition, motivation and understanding (pp. 21-29). London: Lawrence Erlbaum Associates, Inc.

Nuttall, C. (2000). Teaching reading skills in a foreign language. Oxford: MacMillan Heinemann.

Palinscar, A., \& Brown, A. L. (1984).Reciprocal teaching of comprehension-fostering and comprehension-monitoring activities. Cognition \& Instruction, 1(2), 117. doi: 10.1207/ s1532690xci0102_1

Piaget, J. (1971). The theory of stages in cognitive development. In D. R. Green (Ed.), Measurement and Piaget (pp.1-11). New York: McGraw-Hill.

Schiff, R., \& Calif, S. (2004). An academic intervention program for EFL university students with reading disabilities. Journal of Adolescent and Adult Literacy, 48(2), 102-113. doi: 10.1598/ JAAL.48.2.2

Son, L. K., \& Schwartz, B. L. (2002).The relationship between metacognitive monitoring and control. In T. J. Perfect \& B. L. Schwartz (Eds.). Applied metacognition (pp. 15-38). New York: Cambridge University Press. doi: 10.1017/CBO9780511489976.003

Sternberg, R. J. (1986). Critical thinking: Its nature, measurement, and improvement National Institute of Education. Retrieved from: http://eric.ed.gov/PDFS/ED272882.pdf.

Strauss, A., \& Corbin, J. (1990). Basics of qualitative research. California: Sage Publications.

Thiede, K. W., Anderson, M. M., \& Therriault, D. (2003). Accuracy of metacognitive monitoring affects learning of texts. Journal of Educational Psychology, 95(1), 66. doi: 10.1037/00220663.95.1.66

Wei, Y. (2005). The relationship between phonological awareness and reading ability of Thai students in English and Thai primary schools of Thailand. Curriculum \& Instruction, Theses and Dissertations: UM Theses and Dissertations (UMI No. 3175161). ProQuest Information and Learning: Collage Park, MD.

Vygotsky, L. S. (1978). The mind in society. Cambridge, MA: Harvard University Press. (Original work published 1938)

Zimmerman,B.J.(1998).Academicstudyingand thedevelopmentofpersonalskill:Aself-regulatory perspective. Educational Psychologist, 33(2/3), 73-86. doi: 10.1080/00461520.1998.9653292

Original manuscript received September 12, 2015 Revised manuscript accepted July 27, 2016 First published online March 31, 2017 